\title{
Modal Sosial dan Hubungannya dengan Kesejahteraan Petani Plasma PT. Kresna Duta Agroindo di Desa Tanah Abang Kecamatan Pamenang Kabupaten Merangin Provinsi Jambi
}

\author{
Nurjayanti ${ }^{1)}$, Rosyani $^{2)}$, Aulia Farida ${ }^{2)}$ \\ 1) Alumni Jurusan Agribisnis Fakultas Pertanian Universitas Jambi \\ 2) Staf Pengajar Jurusan Agribisnis Fakultas Pertanian Universitas Jambi \\ Email :yanti.casper@yahoo.co.id
}

\begin{abstract}
Abstrak
Modal sosial merupakan bentuk jaringan kerja sosial dan ekonomi di masyarakat yang terjadi antara individu baik formal maupun informal yang bermanfaat dan menguntungkan. Konsep modal sosial yang terdiri dari kepercayaan, norma, jaringan. Modal sosial digunakan masyarakat dalam bermitra pada perusahaan.Selain itu Modal sosial dapat meningkatkan kesejahteraan.Penelitian ini bertujuan untuk mengetahui tingkat kesejahteraan petani plasma dan hubungan modal sosial dengan kesejahteraan masyarakat petani plasma di Desa Tanah Abang Kecamatan Pamenang Kabupaten Merangin.Pemilihan lokasi dilakukan secara purposive dilatar belakangi karena Desa Tanah Abang mayoritas Petani Plasma dan dekat dengan perusahaan kelapa sawit.Jenis data dalam penelitian ini meliputi data primer dan data skunder.Data di analisis secara deskriptif melalui Tabel distribusi frekuensi.Uji analisis yang digunakan adalah uji dengan motode Chi-Square $\left(\mathrm{X}^{2}\right)$. Hasil penelitian menunjukkan : 1) penerapan modal sosial yang terdiri dari kepercayaan dengan kategori tinggi 52,38 persen, norma dengan kategori 53,57 persen, dan jaringan dengan kategori 54,76 persen. 2) kesejahteraandilihat dari dua pendekatan yaitu kesejahteraan ekonomi objektif kategori tinggi 55,95 persen, kesejahteraan ekonomi subjektif (kepuasan pemenuhan kebutuhan pangan kategori tinggi 55,95 persen, non-pangan kategori tinggi 57,14 persen dan investasi kategori sebesar 55,95 persen). 3) hubungan modal sosial dengan kesejahteraan masyarakat petani plasma tergolong kuat.
\end{abstract}

Kata kunci :Modal Sosial, Kesejahteraan Ekonomi Objektif, Kesejahteraan Ekonomi Subjektif

\begin{abstract}
Social capital is a form of social and economic networks in the community that occurred between individuals in both formal and informal beneficial and profitable. The concept of social capital which consists of beliefs, norms, and networks. Social capital used by the people in the partner company. Moreover Social capital can improve wellbeing. This study aims to determine the level of welfare of farmers and social capital relationships with the people's welfare farmers in the village of Tanah Abang subdistrict Pamenang Merangin. The choice of location is done purposively, against the background as the village of Tanah Abang majority of smallholder and close to the palm oil companies. The type of data in this study include primary data and secondary data. Data was analyzed descriptively through frequency distribution table. Test analysis is motode test with Chi-Square (X2). The results showed: 1) the application of social capital consisting of trust with the high category 52.38 percent, 53.57 percent norm by
\end{abstract}


category, and network with 54.76 percent category. 2) well-being viewed from two approaches, namely the economic well-being of high category 55.95 percent objective, subjective economic welfare (satisfaction of food needs high category 55.95 percent, non-food category 57.14 percent higher at 55.95 and investments category percent). 3) the relationship of social capital to the welfare of the farming community and the differences in plasma relatively strong.

Keywords: social capital, economic well-being objective, economic subjective well-being

\section{PENDAHULUAN}

Masyarakat pedesaan tidak lepas dari hubungan sosial, begitu juga masyarakat yang berada diperkotaan. Dalam berinteraksi modal sosial diperlukan dari setiap individu masyarakat.Modal sosial memiliki beberapa pengertian dari berbagai ahli seperti, Putman (1993) dalam Alfiasari, (2009) mengatakan bahwa modal sosial itu karakteristik organisasi sosial, seperti jaringan, norma-norma dan kepercayaan sosial, yang mempermudah koordinasi dan kerjasama untuk manfaat bersama.Menurut Suandi (2007), bahwa modal sosial dalam hal ini asosiasi lokal dan karakter masyarakat secara kualitas dapat mempengaruhi tingkat kesejahteraan ekonomi keluarga. Modal sosial sangat bermanfaat dikalangan masyarakat dibidang pertanian yang memiliki tujuan untuk meningkatkan taraf hidup masyarakat.Kesejahteraan rumah tangga merupakan salah satu indikator kesejahteraan yang diukur dari pendapatan dan kepuasan masyarakat.

Mustofa (2012) dalam Sara Endarwati, (2013) dalam penelitiannya menjelaskan konsep modal sosial yang menekankan pada kerjasama yang dilakukan antar masyarakat. Kerjasama yang dibangun terkait dengan faktor rasa saling percaya, norma dan Jaringan. Kepercayaan merupakan suatu nilai yangditunjukkan oleh adanya prilaku jujur, tertaur dan kerjasama berdasarkan norma-norma yang dianut bersama. Norma merupakan susunan dari pemahaman terhadap nilai-nilai kehidupan serta harapan yang diyakini dan dijalankan oleh sekolompok orang. Norma sosial dapat berupa aturanaturan tidak tertulis dalam hubungan antar rumah tangga di dalam komunitas, nilai-nilai tradisional yang sudah ada turun temurun, dan nilai-nilai agama yang diyakini dalam menjalin hubungan sosial (Alfiasari et al).Jaringan sosial adalah hubungan-hubungan yang terbentuk antara kelompok dengan kelompok lain.

Cara mengukur kesejahteraan dapat dilihat dari dua pendekatan, yakni : Kesejahteraan diukur dengan pendekatan objektif melihat pendapatan dan proxy pengeluaran, dan Kesejahteraan diukur dengan pendekatan subjektif diukur dari tingkat kepuasan yang dirasakan oleh masyarakat sendiri bukan oleh orang lain (Milliganet al., (2006:22) dalam Suandi, (2014).. Kecamatan pamenang salah satu kecamatan yang ada di kabupaten merangin, mayoritas masyarakat kecamtan pamenang adala bekerja sebagai petani, yaitu petani perkebunan seperti karet dan kelapa sawit.Desa tanah Abang merupakan salah satu desa yang ada di kecamtan pamenang, masyarakat desa tanah abang mayoritas bekerja sebagai petani yaitu petani perkebunan komditi kelapa sawit dengan cara bermitra kepada perusahaan.Tiga kategori dalam modal sosial digunakan masyarakat dalam bermitra terhadap perusahaan.Maka dengan adanya modal sosial yang dimiliki kesejahteraan masyarakat dapat meningkat.Sehingga penelitian mengenai modal sosial dan hubungannya dengan kesejahteraan itu penting.Dari hal-hal yang melatar belakangi penulis dalam menyusun, perlu kiranya penulis merumuskan masalah untuk lebih memperjelas maksud dan tujuan penelitian 
ini.Bagaimana tingkat kesejahteraan petani plasma di Desa Tanah Abang, Apakah modal sosial berhubungan dengan kesejahteraan di Desa Tanah Abang.

Adapun yang menjadi tujuan dalam penelitian ini adalah Untuk mengetahui bagaimana tingkat kesejahteraan petani plasma di Desa Tanah Abang. Untuk mengetahui bagaimana modal sosial berhubungan dengan kesejahteraan petani plasma di Desa Tanah Abang.

\section{METODE PENELITIAN}

Penelitian ini di laksanakan di Desa Tanah Abang Kecamatan Pamenang Kabupaten Merangin.Pemilihan lokasi dilakukan berdasarkan pertimbangan bahwa di Desa Tanah Abang salah satu desa yang hampir rata-rata mengusahakan pertanian di sektor perkebunan.Desa Tanah Abang sebagian besar menjadi petani plasma.Dimana dalam menjalin hubungan kerjasama pada perusahaan plasma masyarakat harus memiliki modal sosial yang tinggi.Dengan adanya modal sosial maka dapat dilihat adanya hubungan kesejahteraan petani plasma.Objek penelitian ini adalah petani yang mengusahakan usahatani kelapa sawit yang bermitra kepada perusahaan.Penelitian ini akan dilaksanakan dari bulan September sampai Oktober 2015. Metode penelitian yang digunakan adalah metode deskriptif dan pengumpulan data, data yang digunakan adalah data primer dan data skunder.Data primer diperoleh dari hasil wawancara langsung dengan responden melalui daftar pertanyaan (kuisioner), dan data skunder.Dari 14 Desa yang ada di Kecamatan Pamenang meneliti satu desa sebagai sampel yaitu Desa Tanah Abang sebagai desa yang sebagian besar masyarakat bertani di bidang perkebunan yaitu kelapa sawit secara plasma.Pengambilan sampel di desa tersebut dilakukan secara sengaja, karena desa tersebut dekat dengan perusahaan kelapa sawit.Desa Tanah Abang memiliki 4 dusun dan 20 RT yang terdiri dari 884 kepala keluarga dengan jumlah penduduk sebanyak 4087 jiwa. Terdapat 520 kepala keluarga yang bermitra kepada perusahaan.Dari 520 kepala keluarga yang bermitra kepada perusahaan maka dalam menentukan jumlah sampel dalam penelitian ini ditentukan dengan menggunakan rumus dari Taro Yamane. Pada penelitian ini objek lebih dari 100 orang maka presisi yang diambil sebesar $10 \%$ dengan rumus sebagai berikut:

$$
\mathrm{n}=\frac{N}{N d^{2}+1}
$$

Dimana:

$\mathrm{n}=$ Jumlah Sampel

$\mathrm{N}=$ Jumlah Populasi Petani sasaran

$d^{2}=$ Tingkat Presisi (ditetapkan 10\% dengan tingkat kepercayaan 95\%)

Berdasarkan rumus diatas, diperoleh jumlah sampel sebagai berikut :

$$
\begin{aligned}
& \mathrm{n}=\frac{520}{520 x(0,1)^{2}+1} \\
& \mathrm{n}=83,87 \text { menjadi } 84 \text { Responden }
\end{aligned}
$$

Dari perhitungan sampel dengan menggunakan rumus diatas, maka diperoleh jumlah sampel sebanyak 84 responden petani plasma kelapa sawit. Kemudian jumlah sampel di Desa Tanah Abang yang akan dijadikan responden dipilih berdasarkan setiap RT yang ada di desa tersebut, secara proportionate random sampling dengan rumus : ni $=\frac{N i}{N} n$

Dimana :

ni = Jumlah sampel menurut stratum

$\mathrm{Ni} \quad=$ Jumlah populasi menurut stratum

$\mathrm{n} \quad$ = Jumlah sampel seluruhnya 
$\mathrm{N}$

= Jumlah populasi seluruhnya

Setiap RT diambil rata-rata $4-5$ responden dari setiap RT Teknik penarikan sampel selanjutnya dilakukan dengan metode acak sederhana (Simpel Random Sampling)cara pengambilan sampel dari anggota populasi yang tergabung dalam petani plasma karena setiap populasi memiliki kesempatan yang sama.Untuk mengetahui hubungan modal sosial terhadap kesejahteraan masyarakat petani plasma digunakan statistik non parametrik melalui uji Chisquare $\left(X^{2}\right)$. Menurut Siagel (1992), uji chi square kooefisien kontingensi (c) $2 \times 2$ dengan $\mathrm{N}$ ada diantara 20 sampai 40 dapat dihitung dengan ketentuan sebagai berikut.

Apabila sel berisi frekuensi $\geq 5$, maka rumus yang digunakan:

$\left(\mathrm{X}^{2}\right)=\frac{n\|a d-b c\|^{2}}{(a+b)(c+d)(a+c)(b+d)}: d b=1$

Adapun Tabelnya adalah sebagai berikut:

Model Analisis Uji Chi-square dengan kontingensi (C) $2 \times 2$

\begin{tabular}{cccc}
\hline & \multicolumn{2}{c}{ Tingkat Kesejahteraan } & \\
\cline { 2 - 4 } Modal Sosial & Tinggi & Rendah & Jumlah \\
\hline Tinggi & $\mathrm{A}$ & $\mathrm{B}$ & $\mathrm{A}+\mathrm{B}$ \\
Rendah & $\mathrm{C}$ & $\mathrm{D}$ & $\mathrm{C}+\mathrm{D}$ \\
\hline Jumlah & $\mathrm{A}+\mathrm{C}$ & $\mathrm{B}+\mathrm{D}$ & $\mathrm{N}$
\end{tabular}

Nilai $X^{2}$ hitung dengan derajat bebas $(\mathrm{db})=1$ pada tingkat keprcayaan $95 \%$ adalah 3,84. Dalam pengujian $X^{2}$ hitung dibandingkan dengan nilai $X^{2} T a b e l$, dengan ketentuan sebagai berikut:

- Jika $x^{2}$ hitung $\left[\leq x^{2} \alpha=5 \% d b=(b-1)(k-1)\right]$ terima Ho

- Jika $x^{2}$ hitung $\left[\geq x^{2} \propto=5 \% d b=(b-1)(k-1)\right]$ tolak Ho

$\mathrm{Ho}=$ Tidak terdapat hubungan modal sosial terhadapkesejahteraan petani plasma

$\mathrm{H}_{1}=$ Terdapat hubunganmodal sosial terhadapkesejahteraan petani plasma

Yang kemudian dilanjutkan dengan mencari nilai C (koefisien kontingensi), dengan

rumus sebagai berikut :Chit $=\sqrt{\frac{\mathrm{x}^{2}}{N+\mathrm{x}^{2}}}$

Dimana :

$\mathrm{N}=$ Jumlah Sampel

$X^{2}=$ Nilai Chi Square

$\mathrm{C}=$ koefisien kontingensi, nilai ini terletak diatara $0-0,707$

Selanjutnya untuk mengukur keeratan hubungan digunakan formulasi:

Keterangan :

$$
C \max =\sqrt{\frac{m-1}{m}}=\sqrt{\frac{1}{2}}=0,007 r=\frac{c h i t}{c m a x} r=\frac{\sqrt{\frac{\mathrm{x}^{2}}{\mathrm{x}^{2}+\mathrm{N}}}}{\sqrt{\frac{m-1}{m}}}
$$

$$
\begin{aligned}
& r=\text { Koefisien keeratan hubungan } \\
& x^{2}=\text { Nilai Chi-Square } \\
& N=\text { Jumlah sampel } \\
& m=\text { Jumlah kolom/baris pada tabulasi silang }
\end{aligned}
$$

Dengan kategori :

a. Hubungan digolongkan lemah apabila nilai terletak antara $0-0,353$

b. Hubungan digolongkan kuat apabila nilai terletak antara 0,353-0,707

Selanjutnya untuk nilai $\mathrm{n}$ (ukuran sampel) $>10$ dengan mempergunakan Tabel nilai $\mathrm{t}$ sampel dapat dihitung dengan $: \boldsymbol{t}_{\text {hit }}=\sqrt{\frac{\boldsymbol{N - 2}}{1-(\boldsymbol{r})^{2}}}$ dimana: 
$\mathrm{HO}: \mathrm{r}=\mathrm{O}$

$\mathrm{H} 1: r \neq 0$

- Jika thitung[ $\leq \mathrm{t}$ Tabel $=(\alpha=5 \% \mathrm{db}=\mathrm{N}-2)]$ terima Ho

- Jika thitung[ $\geq \mathrm{t} \mathrm{Tabel}=(\propto=5 \% \mathrm{db}=\mathrm{N}-2)$ ] tolak Ho

Dimana:

HO = perbedaan hubungan modal sosial dengan kesejahteraan masyarakat petani palsma tidak menyebabkan perbedaan kesejahteraan masyarakat petani plasma.

$\mathrm{H} 1$ = perbedaan hubungan modal sosial dengan kesejahteraan amsyarakat petani plasma menyebabkan perbedaan kesejahteraan masyarakat petani plasma.

\section{Penerapan modal sosial}

\section{HASIL DAN PEMBAHASAN}

Kepercayaa salah satu konsep dasar dalam modal sosial, dapat ditunjukkan dengan jujur.

Tabel 1.Distribusi Frekuensi Petani Sampel Konsep Kepercayaa di Daerah Penelitian Tahun 2015

\begin{tabular}{lcc}
\hline Kepercayaan & Frekuensi & Persentase \\
\hline Tinggi & 44 & 52,381 \\
Rendah & 40 & 47,619 \\
\hline Jumlah & 84 & 100 \\
\hline
\end{tabular}

Sumber: Olahan Data Primer Tahun 2015

Tabel 1 memperlihatkan bahwa modal sosial tinggi dilihat dari konsep dasar yaitu kepercayaan, ini menandakan bahwa nilai modal sosial di daerah penelitian baik secara langsung maupun tidak langsung berhubungan secara nyata. Tingkat kepercayaan petani responden di lapangan sebesar 52,38\% ini masuk kedalam kategori tinggi. Kepercayaan yang dapat dilihat dari teraturnya kegiatan meninbang kelapa sawit yang dilakukan 2 minggu sekali.Kerjasama yang baik antara petani dan perusahaan.Petani plasma juga memiliki harapan kepada perusahaan yaitu harga kelapa sawit agar stabil serta pola replanting berjalan seperti dulu yaitu berpola PIR.

Norma muncul dari pertukaran yang saling menguntungkan (blau 11963: fukuyama 1999) dalam Robert Lawang, (2005). Dalam pertukaran itu keuntungan hanya dinikmati oleh salah satu pihak saja, pertukaran sosial selanjutnya pasti tidak akan terjadi, karena itu norma yang muncul bukan sekali melalui pertukaran.

Tabel 2.Distribusi Frekuensi Petani Responden dalam Konsep Norma di Daerah Penelitian Thun 2015

\begin{tabular}{lcc}
\hline Norma & Frekuensi & Persentase \\
\hline Tinggi & 45 & 53,57 \\
Rendah & 39 & 46,42 \\
\hline Jumlah & 84 & 100 \\
\hline
\end{tabular}

Sumber: Olahan Data Primer Tahun 2015

Tabel 2 memperlihatkan bahwa norma memiliki nilai tinggi. Dapat dilihat norma petani pada daerah penelitian sebesar 53,57 persen, sedangkan dalam kategori rendah sebesar 46,42 persen. Norma di daerah penelitian dapat dilihat berupa aturan yang dibuat oleh prusahaan yang disepakati bersama petani plasma.Norma yang telah diterapkan dari perusahaan dipatuhi oleh petani.Hubungan timbal balik yang terjadi antara perusahaan dan petani plasma dalam program CSR.

Jaringan berupa hubungan sosial yang diikat dengan kepercayaan, dapat berupa bentuk strategik dapat pula dalam bentuk moralistik. 
Tabel 3.Distribusi Frekuensi Petani Responden dalam Konsep Jaringan di Daerah Penelitian Tahun 2015

\begin{tabular}{lcc}
\hline Jaringan & Frekuensi & Persentase \\
\hline Tinggi & 46 & 54,76 \\
Rendah & 38 & 33,33 \\
\hline Jumlah & 84 & 100 \\
\hline
\end{tabular}

Sumber: Olahan Data Primer Tahun 2015

Tabel 3 memperlihatkan bahwa penerapan modal sosial dari konsep dasar berupa jaringan cukup tinggi, yaitu dalam kategori tinggi sebesar 54,76 persen. Hal ini tergolng kuat, karena jaringan yang terlihat di petani responden yaitu jaringan terhadap perusahaan yaitu pertukaran informasi.Solidaritas yang terjadi antara petani plasma namun juga terdapat solidaritas yang diberikan oleh perusahaan seperti CSR bantuan sosial.

\section{Kesejahteraan}

Kesejahteraan ekonomi objektif dapat dilihat melalui proxy pengeluaran keluarga perkapita/bulan.Pengeluaran keluarga dapat diperuntukkan untuk memenuhi kebutuhan sehari-hari yaitu kebutuhan dasar dan kebutuhan lainnya, meliputi kebutuhan pangan, non-pangan dan investasi.

Tabel 4.Distribusi Frekuensi Petani Sampel berdasarkan Kesejahteraan Ekonomi Objektif di Daerah Penelitian Tahun 2015

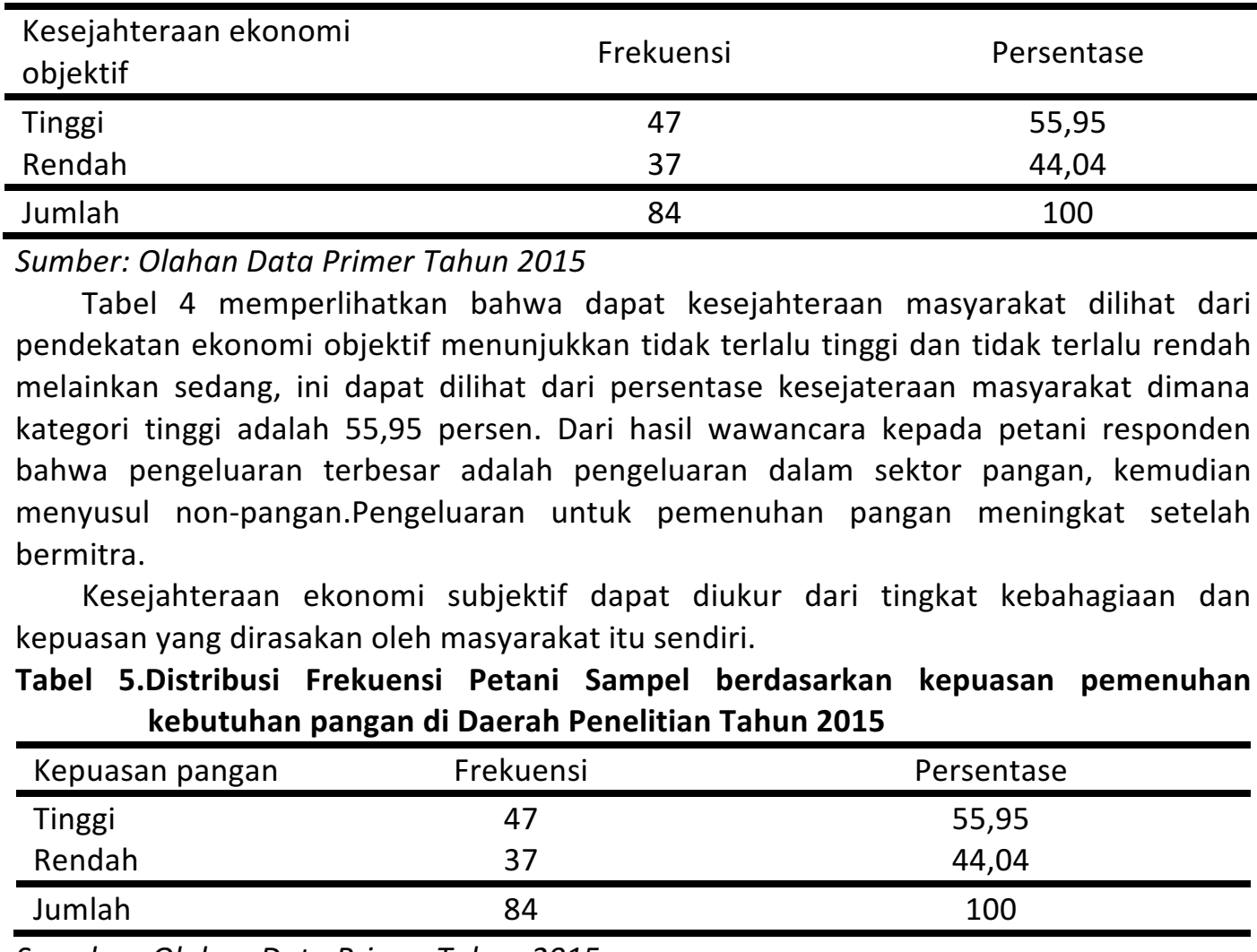

Susmber: Olahan Data Primer Tahun 2015 
Tabel 5 memperlihatkan bahwa kepuasan akan pemenuhan kebutuhan pangan tinggi sebesar 55,95 persen. Kepuasan akan pemenuhan kebutuhan pangan dilihat dari kepuasan akan konsumsi lauk-pauk yang beragam setiap harinya, di daerah penelitian petani responden mengaku puas karena dapat mengkonsumsi lauk-pauk yang berbeda disetiap harinya.

Tabel6.Distribusi Frekuensi Petani Sampel berdasarkan kepuasan pemenuhan kebutuhan non-pangan di Daerah Penelitian Tahun 2015

\begin{tabular}{lcc}
\hline Kepuasan non-pangan & Frekuensi & Persentase \\
\hline Tinggi & 48 & 57,14 \\
Rendah & 36 & 42,85 \\
\hline Jumlah & 84 & 100 \\
\hline
\end{tabular}

Sumber: Olahan Data Primer Tahun 2015

Tabel 6 memperlihatkan bahwa kepuasan akan pemenuhan kebutuhan non-pangan tinggi sebesar 57,14 persen. Kepuasan akan pemenuhan kebutuhan non-pangan mengkat.

Tabel 7.Distribusi Frekuensi Petani Sampel berdasarkan kepuasan pemenuhan investasi di Daerah Penelitian Tahun 2015

\begin{tabular}{lcc}
\hline Kepuasan investasi & Frekuensi & Persentase \\
\hline Tinggi & 47 & 55,95 \\
Rendah & 37 & 44,04 \\
\hline Jumlah & 84 & 100 \\
\hline
\end{tabular}

Sumber: Olahan Data Primer Tahun 2015

Tabel 7 memperlihatkan bahwa kepuasan akan pemenuhan kebutuhan non-pangan tinggi sebesar 55,95 persen.Kepuasan akan pemenuhan investasi berupa pemenuhan kebutuhan pendidikan dan kesehatan, masyarakat puas dengan berplasma maka dapat membayar sekolah dengan mudah dan berobat kerumah sakit dapat dibayar.

\section{Hubungan modal sosial dengan kesejahteraan}

Hubungan dimensi Kepercayaan dengan kesejahteraan Ekonomi Objektif Masyarakat Petani Plasma

Tabel 8.Kontingensi Hubungan antara Kepercayaan dengan Kesejahteraan Ekonomi Objektif Masyarakat di Daerah Penelitian Tahun 2015

\begin{tabular}{cccc}
\hline \multirow{2}{*}{ Kepercayaan } & \multicolumn{2}{c}{ Kesejahteraan ekonomi objektif Masyarakat } & \multirow{2}{*}{ Jumlah } \\
\cline { 2 - 4 } & Tinggi & Rendah & \\
\hline Tinggi & 35 & 9 & 44 \\
Rendah & 12 & 28 & 40 \\
\hline Jumlah & 47 & 37 & 84 \\
\hline
\end{tabular}

Sumber: Olahan Data Primer Tahun 2015

Tabel 8 memperlihatkan bahwa kepercayaan tinggi maka tingkat kesejahteraan ekonomi objektif tinggi pula. Berdasarkan hasil uji statistik yaitu uji Chi-Square di peroleh nilai $x^{2}=17,564>x^{2} \operatorname{tab}(\alpha=5 \% \mathrm{db}=1)=3,84$ maka keputusan terima H1yang artinya terdapat hubungan secara nyata antara kepercayaan dengan kesejahteraan ekonomi objektif masyarakat petani plasma, hal ini berbanding terbalik dengan penelitian tentang Modal Sosial dan Kesejahteraan Ekonomi Keluarga di Provinsi Jambi (Suandi, 2014).Koofisien kontingensi Chit=0,415 yang artinya derajat hubungan tergolong kuat karena $C$ hit $=0,415$ dan $C \max =0,707$. Selanjutnya $\boldsymbol{t}_{\text {hit }}=6,578>$ dari $\boldsymbol{t}$ 
table $(1,9958)$ maka terima $\mathrm{H} 1$ artinya perbedaan tinggi rendahnya kepercayaan menyebabkan perbedaan tinggi rendahnya kesejahteraan ekonomi objektif masyarakat petani plasma.

Tabel 9.Kontingensi Hubungan antara Norma dengan Kesejahteraan Ekonomi Objektif Masyarakat di Daerah Penelitian Tahun 2015

\begin{tabular}{cccc}
\hline Norma & Kesejahteraan ekonomi objektif Masyarakat & Jumlah \\
\hline Tinggi & Tinggi & Rendah & \\
\hline Rendah & 31 & 14 & 45 \\
\hline Jumlah & 16 & 23 & 39 \\
\hline
\end{tabular}

Sumber: Olahan Data Primer Tahun 2015

Tabel 9 memperlihatkan bahwa norma tinggi maka tingkat kesejahteraan ekonomi objektif tinggi pula. Berdasarkan hasil uji statistik yaitu uji Chi-Square di peroleh nilai $x^{2}$ $=6,581>x^{2} \operatorname{tab}(\alpha=5 \% \mathrm{db}=1)=3,84$ maka keputusan terima H1yang artinya terdapat hubungan secara nyata antara normadengan kesejahteraan ekonomi objektif masyarakat petani plasmahal ini berbanding terbalik dengan penelitian tentang Modal Sosial dan Kesejahteraan Ekonomi Keluarga di Provinsi Jambi (Suandi, 2014). Koofisien kontingensi Chit=0,275 yang artinya derajat hubungan lemah karena $C$ hit $=0,275$ dan $C$ $\max =0,707$. Selanjutnyat ${ }_{\text {hit }}=3,812>$ dari $\boldsymbol{t}$ table $(1,9958)$ maka terima H1artinya perbedaan tinggi rendahnya norma menyebabkan perbedaan tinggi rendahnya kesejahteraan ekonomi objektif masyarakat petani plasma.

Tabel 10.Kontingensi Hubungan antara kepercayaan dengan Kesejahteraan Ekonomi Objektif Masyarakat di Daerah Penelitian Tahun 2015

\begin{tabular}{cccc}
\hline \multirow{2}{*}{ Jaringan } & \multicolumn{1}{c}{ Kesejahteraan ekonomi objektif Masyarakat } & \multirow{2}{*}{ Jumlah } \\
\cline { 2 - 4 } & Tinggi & Rendah & \\
\hline Tinggi & 31 & 15 & 46 \\
Rendah & 16 & 22 & 38 \\
\hline Jumlah & 47 & 37 & 84 \\
\hline
\end{tabular}

Sumber: Olahan Data Primer Tahun 2015

Tabel 10 memperlihatkan bahwa jaringan tinggi maka tingkat kesejahteraan ekonomi objektif tingg pula.Berdasarkan hasil uji statistik yaitu uji Chi-Square di peroleh nilai $x^{2}=5,398>x^{2} \operatorname{tab}(\alpha=5 \% \mathrm{db}=1)=3,84$ maka keputusan terima H1yang artinya terdapat hubungan secara nyata antara jaringan dengan kesejahteraan ekonomi objektif masyarakat petani plasma,hal ini berbanding terbalik dengan penelitian tentang Modal Sosial dan Kesejahteraan Ekonomi Keluarga di Provinsi Jambi (Suandi, 2014). Koofisien kontingensi Chit=0,245yang artinya derajat hubungan tergolong lemah karena $\mathrm{C}$ hit $=$ 0,245 dan $C \max =0,707$. Selanjutnyat ${ }_{\text {hit }}=3,337>$ dari $\boldsymbol{t}_{\text {table }}(1,9958)$ maka terima $\mathrm{H}_{1}$ artinya perbedaan tinggi rendahnya jaringan menyebabkan perbedaan tinggi rendahnya kesejahteraan ekonomi objektif masyarakat petani plasma.

Hubungan dimensi Kepercayaan dengan Kepuasan pemenuhan kebutuhan Pangan pada Masyarakat Petani Plasma

Kesejahteraan subjektif yang dilihat dari tingkat kepuasan yang dirasakan setiap individu. 
Tabel11. Kontingensi Hubungan antara Kepercayaan dengan Kepuasan pemenuhan kebutuhan Pangan Masyarakat di Daerah Penelitian Tahun 2015

\begin{tabular}{cccc}
\hline \multirow{2}{*}{ Kepercayaan } & \multicolumn{2}{c}{ Kepuasan pemenuhan kebutuhan Pangan } & \multirow{2}{*}{ Jumlah } \\
\cline { 2 - 3 } & Tinggi & Rendah & \\
\hline Tinggi & 33 & 11 & 44 \\
Rendah & 14 & 26 & 40 \\
\hline Jumlah & 47 & 37 & 84
\end{tabular}

Sumber: Olahan Data Primer Tahun 2015

Tabel 11 memperlihatkan bahwa kepercayaan tinggi maka tingkat kepuasan akan pemenuhan kebutuhan pangan tinggi pula. Berdasarkan hasil uji statistik yaitu uji ChiSquare di peroleh nilai $x^{2}=4,441>x^{2} \operatorname{tab}(\alpha=5 \% \mathrm{db}=1)=3,84$ maka keputusan termia H1 yang artinya terdapat hubungan secara nyata antara kepercayaan dengan kepuasan pemenuhan kebutuhan pangan masyarakat petani plasma, hal ini berbanding terbalik dengan penelitian tentang Pengaruh Modal Sosial terhadap Ketahanan Pangan Rumah Tangga Petani (Saraendarwati, 2013). Koofisien kontingensi Chit $=0,224$ yang artinya derajat hubungan tergolong lemah karena $C$ hit $=0,224$ dan $C \max =0,707$. Selanjutnyat hit $=3,016>$ dari $\boldsymbol{t}$ table $(1,9958)$ maka terima $\mathrm{H}_{1}$ artinya perbedaan tinggi rendahnya kepercayaan menyebabkan perbedaan tinggi rendahnya kepuasan dalam pemenuhan kebutuhan pangan pada masyarakat petani plasma.

Tabel12.Kontingensi Hubungan antara Norma dengan Kepuasan pemenuhan kebutuhan pangan Masyarakat di Daerah Penelitian Tahun 2015

\begin{tabular}{cccc}
\hline \multirow{2}{*}{ Norma } & \multicolumn{2}{c}{ Kepuasan pemenuhan kebutuhan Pangan } & \multirow{2}{*}{ Jumlah } \\
\cline { 2 - 3 } & \multicolumn{1}{c}{ Tinggi } & Rendah & \\
\hline Tinggi & 31 & 14 & 45 \\
Rendah & 16 & 23 & 39 \\
\hline Jumlah & 47 & 37 & 84
\end{tabular}

Sumber: Olahan Data Primer Tahun 2015

Tabel 12 memperlihatkan bahwa norma tinggi maka tingkat kepuasan pemenuhan kebutuhan pangan tinggi pula. Berdasarkan hasil uji statistik yaitu uji Chi-Square di peroleh nilai $x^{2}=6,581>x^{2} \operatorname{tab}(\alpha=5 \% \mathrm{db}=1)=3,84$ maka keputusan terima H1yang artinya terdapat hubungan secara nyata antara norma dengan kepuasan pemenuhan kebutuhan pangan pada petani plasma,hal ini berbanding terbalik dengan penelitian tentang Pengaruh Modal Sosial terhadap Ketahanan Pangan Rumah Tangga Petani (Saraendarwati, 2013). Koofisien kontingensi Chit $=0,275$ yang artinya derajat hubungan tergolong lemah. Selanjutnya $\boldsymbol{t}_{\text {hit }}=3,812>$ dari $\boldsymbol{t}_{\text {table }}(1,9958)$ maka terima $\mathrm{H}_{1}$ artinya perbedaan tinggi rendahnya norma menyebabkan perbedaan tinggi rendahnya kepuasan pemenuhan kebutuhan pangan pada masyarakat petani plasma.

Tabel 13.Kontingensi Hubungan antara Jaringan dengan Kepuasan Pemenuhan Kebutuhan Pangan Masyarakat di Daerah Penelitian Tahun 2015

\begin{tabular}{cccc}
\hline \multirow{2}{*}{ Jaringan } & \multicolumn{2}{c}{ Kepuasan pemenuhan kebutuhan Pangan } & \multirow{2}{*}{ Jumlah } \\
\cline { 2 - 3 } & Tinggi & Rendah & \\
\hline Tinggi & 33 & 13 & 46 \\
Rendah & 14 & 24 & 38 \\
\hline Jumlah & 47 & 37 & 84 \\
\hline
\end{tabular}

Sumber: Olahan Data Primer Tahun 2015 
Tabel 13 memperlihatkan bahwa jaringan tinggi maka tingkat kepuasan dalam pemenuhan kebutuhan pangan tinggi pula.Berdasarkan hasil uji statistik yaitu uji ChiSquare di peroleh nilai $x^{2}=3,983>x^{2} \operatorname{tab}(\alpha=5 \% \mathrm{db}=1)=3,84$ maka keputusan terima H1yang artinya terdapat hubungan secara nyata antara jaringan dengan kepuasan dalam pemenuhan kebutuhan pangan pada masyarakat petani plasma,hal ini berbanding terbalik dengan penelitian tentang Pengaruh Modal Sosial terhadap Ketahanan Pangan Rumah Tangga Petani (Saraendarwati, 2013). Koofisien kontingensi Chit $=0,212$ yang artinya derajat hubungan tergolong lemah karena $C$ hit $=0,212$ dan $C \max =0,707$. Selanjutnya $\boldsymbol{t}_{\text {hit }}=2,847>$ dari $\boldsymbol{t}_{\text {table }}((1,9958))$ maka terima H1artinya perbedaan tinggi rendahnya jaringan menyebabkan perbedaan tinggi rendahnya kepuasan dalam pemenuhan kebutuhan pangan masyarakat petani plasma.

Hubungan dimensi Kepercayaan dengan Kepuasan pemenuhan kebutuhan NonPangan pada Masyarakat Petani Plasma

Tabel14. Kontingensi Hubungan antara Kepercayaan dengan Kepuasan pemenuhan kebutuhan Non-Pangan pada Masyarakat Petani Plasma di Daerah Penelitian Tahun 2015

\begin{tabular}{cccc}
\hline \multirow{2}{*}{ Kepercayaan } & \multicolumn{2}{c}{ Kepuasan pemenuhan kebutuhan non-pangan } & \multirow{2}{*}{ Jumlah } \\
\cline { 2 - 3 } & Tinggi & Rendah & \\
\hline Tinggi & 34 & 10 & 44 \\
Rendah & 14 & 26 & 40 \\
\hline Jumlah & 48 & 36 & 84
\end{tabular}

Sumber: Olahan Data Primer Tahun 2015

Tabel 14 memperlihatkan bahwa norma tinggi maka tingkat kepuasan pemenuhan kebutuhan non-pangan tinggi pula. Berdasarkan hasil uji statistik yaitu uji Chi-Square di peroleh nilai $x^{2}=15,288>x^{2} \operatorname{tab}(\alpha=5 \% \mathrm{db}=1)=3,84$ maka keputusan terima $\mathrm{H}_{1}$ yang artinya terdapat hubungan secara nyata antara kepercayaan dengan kepuasan dalam pemenuhan kebutuhan non-pangan masyarakat petani plasma,hal ini berbanding terbalik dengan penelitian tentang Hubungan Modal Sosial dengan Ketahanan Pangan dan Kesejahteraan Keluarga di Daerah Perdesaan Kabupaten Tanjung Jabung Timur (Suandi dan Dompak, 2012).. Koofisien kontingensi Chit= 0,392 yang artinya derajat hubungan tergolong kuat karena $C$ hit $=0,392$ dan $C \max =0,707$. Selanjutnya $\boldsymbol{t}_{\text {hit }}=$ $6,026>$ dari $\boldsymbol{t}$ table $(1,9958)$ maka terima $\mathrm{H}_{1}$ artinya perbedaan tinggi rendahnya kepercayaan menyebabkan perbedaan tinggi rendahnya kepuasan pemenuhan kebutuhan non-pangan masyarakat petani plasma.

Tabel15.Kontingensi Hubungan antara Norma dengan Kepuasan pemenuhan kebutuhan Non-Pangan pada Masyarakat Petani Plasma di Daerah Penelitian Tahun 2015

\begin{tabular}{cccc}
\hline \multirow{2}{*}{ Norma } & \multicolumn{2}{c}{ Kepuasan non-pangan } & \multirow{2}{*}{ Jumlah } \\
\cline { 2 - 3 } & Tinggi & Rendah & 45 \\
\hline Tinggi & 31 & 14 & 39 \\
Rendah & 17 & 22 & 84 \\
\hline Jumlah & 48 & 36 & \\
\hline
\end{tabular}

Sumber: Olahan Data Primer Tahun 2015

Tabel 15 memperlihatkan bahwa norma tinggi maka tingkat kepuasan pemenuhan kebutuhan non-pangan tinggi pula. Berdasarkan hasil uji statistik yaitu uji Chi-Square di peroleh nilai $x^{2}=5,460>x^{2} \operatorname{tab}(\alpha=5 \% \mathrm{db}=1)=3,84$ maka keputusan terima $\mathrm{H}_{1}$ yang artinya terdapat hubungan secara nyata antara norma dengan kepuasan dalam 
pemenuhan kebutuhan non-pangan masyarakat petani plasma,hal ini berbanding terbalik dengan penelitian tentang Hubungan Modal Sosial dengan Ketahanan Pangan dan Kesejahteraan Keluarga di Daerah Perdesaan Kabupaten Tanjung Jabung Timur (Suandi dan Dompak, 2012).. koofisien kontingensi Chit $=0,247$ yang artinya derajat hubungan tergolong lemah karena $\mathrm{C}$ hit $=0,247$ dan $\mathrm{C} \max =0,707$. Selanjutnya $\boldsymbol{t}_{\text {hit }}=$ $3,372>$ dari $\boldsymbol{t}$ table $\left((\geq \mathrm{t}\right.$ Tabel $=(\propto=5 \% \mathrm{db}=82=1,9958))$ maka terima $\mathrm{H}_{1}$ artinya perbedaan tinggi rendahnya norma menyebabkan perbedaan tinggi rendahnya kepuasan pemenuhan kebutuhan non-pangan masyarakat petani plasma.

Tabel16. Kontingensi Hubungan antara Jaringan dengan Kepuasan pemenuhan kebutuhan Non-Pangan pada Masyarakat Petani Plasma di Daerah Penelitian Tahun 2015

\begin{tabular}{cccc}
\hline \multirow{2}{*}{ Jaringan } & \multicolumn{2}{c}{ Kepuasan non-pangan } & \multirow{2}{*}{ Jumlah } \\
\cline { 2 - 4 } & Tinggi & Rendah & \\
\hline Tinggi & 33 & 13 & 46 \\
Rendah & 15 & 23 & 38 \\
\hline Jumlah & 48 & 36 & 84 \\
\hline
\end{tabular}

Sumber: olahan data primer tahun 2015

Tabel 16 memperlihatkanbahwa jaringan tinggi maka tingkat kepuasan pemenuhan kebutuhan non-pangan tinggi pula.Berdasarkan hasil uji statistik yaitu uji Chi-Square di peroleh nilai $x^{2}=8,846>x^{2} \operatorname{tab}(\alpha=5 \% \mathrm{db}=1)=3,84$ maka keputusan terima $\mathrm{H}_{1}$ yang artinya terdapat hubungan secara nyata antara jaringan dengan kepuasan dalam pemenuhan kebutuhan non-pangan masyarakat petani plasma,hal ini berbanding terbalik dengan penelitian tentang Hubungan Modal Sosial dengan Ketahanan Pangan dan Kesejahteraan Keluarga di Daerah Perdesaan Kabupaten Tanjung Jabung Timur (Suandi dan Dompak, 2012).. Koofisien kontingensi Chit $=0,308$ yang artinya derajat hubungan tergolong kuat karena Chit $=0,308$ dan $\mathrm{Cmax}=0,707$. Selanjutnya $\boldsymbol{t}_{\text {hit }}=4,376$ $>$ dari $\boldsymbol{t}$ table $(1,9958)$ maka terima $\mathrm{H}_{1}$ artinya perbedaan tinggi rendahnya jaringan menyebabkan perbedaan tinggi rendahnya kepuasan pemenuhan kebutuhan nonpangan masyarakat petani plasma.

Hubungan dimensi Kepercayaan dengan Kepuasan Investasi pada Masyarakat Petani Plasma

Tabel17. Kontingensi Hubungan antara Kepercayaan dengan Kepuasan Investasi pada Masyarakat Petani Plasma di Daerah Penelitian Tahun 2015

\begin{tabular}{cccc}
\hline \multirow{2}{*}{ Kepercayaan } & \multicolumn{2}{c}{ Kepuasan Investasi } & \multirow{2}{*}{ Jumlah } \\
\cline { 2 - 3 } & Tinggi & Rendah & 44 \\
\hline Tinggi & 34 & 10 & 40 \\
Rendah & 13 & 27 & 84
\end{tabular}

Sumber: Olahan Data Primer Tahun 2015

Tabel 17 memperlihatkanbahwa kepercayaan tinggi maka tingkat kepuasan dalam investasi tinggi pula.Berdasarkan hasil uji statistik yaitu uji Chi-Square di peroleh nilai $x^{2}$ $=17,041>x^{2} \operatorname{tab}(\alpha=5 \% d b=1)=3,84$ maka keputusan terima $H_{1}$ yang artinya terdapat hubungan secara nyata antara kepercayaan dengan kepuasan dalam investasi pada masyarakat petani plasma,hal ini berbanding terbalik dengan penelitian tentang Hubungan Modal Sosial dengan Ketahanan Pangan dan Kesejahteraan Keluarga di Daerah Perdesaan Kabupaten Tanjung Jabung Timur (Suandi dan Dompak, 2012).Koofisien kontingensi Chit $=0,410$ yang artinya derajat hubungan tergolong kuat karena Chit $=0,410$ dan Cmax $=0,707$. Selanjutnya $\boldsymbol{t}_{\text {hit }}=6,434>$ dari $\boldsymbol{t}_{\text {table }}(1,9958)$ maka 
terima $\mathrm{H}_{1}$ artinya perbedaan tinggi rendahnya kepercayaan menyebabkan perbedaan tinggi rendahnya kepuasan dalam investasi pada masyarakat petani plasma.

Tabel18. Kontingensi Hubungan antara Norma dengan Kepuasan pemenuhan kebutuhan Investasi pada Masyarakat Petani Plasma di Daerah Penelitian Tahun 2015

\begin{tabular}{cccc}
\hline \multirow{2}{*}{ Norma } & \multicolumn{2}{c}{ Kepuasan Investasi } & \multirow{2}{*}{ Jumlah } \\
\cline { 2 - 3 } & Tinggi & Rendah & 45 \\
\hline Tinggi & 33 & 12 & 39 \\
Rendah & 14 & 25 & 84
\end{tabular}

Sumber: Olahan Data Primer Tahun 2015

Tabel 18 memperlihatkanbahwa norma tinggi maka tingkat kepuasan dalam investasi tinggi pula. Berdasarkan hasil uji statistik yaitu uji Chi-Square di peroleh nilai $x^{2}$ $=17,041>x^{2} \operatorname{tab}(\alpha=5 \% \mathrm{db}=1)=3,84$ maka keputusan terima $\mathrm{H}_{1}$ yang artinya terdapat hubungan secara nyata antara kepercayaan dengan kepuasan dalam investasi pada masyarakat petani plasma, hal ini berbanding terbalik dengan penelitian tentang Hubungan Modal Sosial dengan Ketahanan Pangan dan Kesejahteraan Keluarga di Daerah Perdesaan Kabupaten Tanjung Jabung Timur (Suandi dan Dompak, 2012). Koofisien kontingensi Chit $=0,410$ yang artinya derajat hubungan tergolong kuat karena Chit $=0,410$ dan $C \max =0,707$. Selanjutnya $\boldsymbol{t}_{\text {hit }}=6,434>$ dari $\boldsymbol{t}_{\text {table }}(1,9958)$ maka terima $\mathrm{H}_{1}$ artinya perbedaan tinggi rendahnya kepercayaan menyebabkan perbedaan tinggi rendahnya kepuasan dalam investasi pada masyarakat petani plasma.

Tabel19. Kontingensi Hubungan antara Jaringan dengan Kepuasan Investasi pada Masyarakat Petani Plasma di Daerah Penelitian Tahun 2015

\begin{tabular}{|c|c|c|c|}
\hline \multirow{2}{*}{ Jaringan } & \multicolumn{2}{|c|}{ Kepuasan investasi } & \multirow{2}{*}{ Jumlah } \\
\hline & Tinggi & Rendah & \\
\hline Tinggi & 33 & 13 & 46 \\
\hline Rendah & 15 & 23 & 38 \\
\hline Jumlah & 48 & 36 & 84 \\
\hline
\end{tabular}

Sumber: olahan data primer tahun 2015

Tabel 19 memperlihatkan bahwa jaringan tinggi maka tingkat kepuasan investasi tinggi pula.Berdasarkan hasil uji statistik yaitu uji Chi-Square di peroleh nilai $x^{2}=8,846$ $>x^{2} \operatorname{tab}(\alpha=5 \% \mathrm{db}=1)=3,84$ maka keputusan terima $\mathrm{H}_{1}$ yang artinya terdapat hubungan secara nyata antara jaringan dengan kepuasan investasi masyarakat petani plasma,hal ini berbanding terbalik dengan penelitian tentang Hubungan Modal Sosial dengan Ketahanan Pangan dan Kesejahteraan Keluarga di Daerah Perdesaan Kabupaten Tanjung Jabung Timur (Suandi dan Dompak, 2012). Koofisien kontingensi Chit=0,308 yang artinya derajat hubungan tergolong kuat karena Chit $=0,308$ dan $\mathrm{Cmax}=0,707$. Selanjutnya $\boldsymbol{t}_{\text {hit }}=4,376>$ dari $\boldsymbol{t}_{\text {table }}(1,9958)$ maka terima $\mathrm{H}_{1}$ artinya perbedaan tinggi rendahnya jaringan menyebabkan perbedaan tinggi rendahnya kepuasan investasi masyarakat petani plasma. 
Berdasarkan hasil penelitian menunjukkan bahwa hubungan modal sosial denga kesejahteraan masyarakat petani plasma di Desa Tanah Abang menunjukkan hasil bahwa modal sosial dan kesejahteraan terdapat hubungan, hasil dari hubungan tersebut dapat dilihat dari kesejahteraan masyarakat di desa tersebut. Kemudian tingkat kesejahteraan masyarakat di desa Tanah Abang termasuk kedalam kategori tinggi yaitu sebesar 57,14 persenyang dilihat dari konsep modal sosial berupa kepercayaan, norma, dan jaringan yang dihubungkan dengan kesejahteraan yang dilihat dari dua pendekatan yaitu kesejahteraan ekonomi objektif dan kesejahteraan ekonomi subjektif.Dimana kesejahteraan ekonomi objektif diukur dari pengeluaran dan pendapatan sedangkan kesejahteraan ekonomi subjektif diukur dari tingkat kepuasan individu akan pemenuhan kebutuhan sehari-hari berupa kebutuhan pangan, non-pangan dan investasi. Dari hasil pengukuran maka tingkat kesejahteraan tinggi dan tingkat kepuasan juga tinggi.

\section{UCAPAN TERIMAKASIH}

Ucapan terima disampaikan pada Dekan Fakultas dan Ketua Jurusan Agribisnis Fakultas Pertanian Universitas Jambi yang telah memfasilitasi pelaksanaan penelitian ini, selain itu ucapan bapak sekretaris desa Tanah Abang Kecamatan Pamenang dan warga yang telah membantu melancarkan penelitian ini.

\section{DAFTAR PUSTAKA}

Alfiasari, 2009. Penguatan Modal Sosial Untuk Perlindungan Rumah Tangga Miskin Dalam Mengoptimalkan Status Gizi Dan Kematangan Sosial Anak.Bogor.Jurnal.http://Www.Smeru.Or.Id/Cpsp/Paper,\%20Abstact,\%20CV/0 201_Alfiasari-Paper.Pdf. (Diakses Pada Tanggal 21 Desember 2015)

Lawang. Robert M Z .2004. Kapital Sosial dalam perspektif sosiologik.FISIS UI Press. Jakarta

Riduwan. 2009. Rumus dan Data dalam Aplikasi Statistika Untuk Penelitian. Alfabeta. Bandung.

Sara Endarwati, 2013.PengaruhModal Sosial Terhadap Ketahanan Pangan Rumah Tangga Petani (Kasus: Rumah Tangga Petani Desa Ciaruteun Ilir, Kecamatan Clbungbulang, Kabupaten Bogor).Jurnal.http://www.academia.edu/6077599/Proposal_Sara_Endarwati_I341 00155_fix. (diakses pada tanggal 21 Desember 2014)

Suandi, 2014. Modal Sosial dan kesejahteraan Keluarga di Daerah Pedesaan Provinsi Jambi. Universitas Negri Semarang.Disertasi.

Suandi dan Dompak Mt Napitupulu, 2012.Hubungan Modal Sosial dengan Ketahanan Pangan dan Kesejahteraan Keluarga di Daerah Perdesaan Kabupaten Tanjung Jabung Timur.Artikel Seminar Nasional. 